\title{
Neurologic Recovery after Anterior Cervical Discectomy and Fusion
}

\author{
Charles L. Lehmann ${ }^{1} \quad$ Jacob M. Buchowski ${ }^{1} \quad$ Geoffrey E. Stoker ${ }^{1} \quad$ K. Daniel Riew ${ }^{1}$ \\ ${ }^{1}$ Department of Orthopaedic Surgery, Washington University in \\ St. Louis, St. Louis, Missouri, United States \\ Global Spine J 2014;4:41-46.

\begin{abstract}
Address for correspondence Jacob M. Buchowski, MD, MS, Associate Professor of Orthopaedic and Neurological Surgery, Department of Orthopaedic Surgery, Washington University in St. Louis, BJC Institute of Health, 425 S. Euclid Avenue, Campus Box 8233, St. Louis, MO 63110, United States (e-mail: buchowskij@wustl.edu).
\end{abstract}

\begin{abstract}
Study Design Retrospective review.

Objective The objective of this study is to describe the natural history of neurologic recovery after anterior cervical discectomy and fusion (ACDF).

Methods Patients between 18 and 80 years of age, diagnosed with cervical radiculopathy, who underwent single-level ACDF and were followed for a minimum of 2 years were identified from a single-center database. Sensory and motor deficits were documented and graded based on physical examination findings at preoperative and postoperative visits, and used to calculate deficit rates.

Results One hundred eighteen patients were included in the study. Mean age was $46 \pm 9.2$ years and mean follow-up time was $3.8 \pm 2.1$ years. At the time of surgery, $66 \%$ had a sensory deficit. Recovery of sensory function was seen in $85 \%$ of patients within 1 year. At final follow-up, new sensory deficits had developed in $30 \%$ of patients, $60 \%$ of whom had adjacent-level sensory deficits. Patients with preoperative sensory

Keywords

- anterior cervical discectomy and fusion

- neurologic

- recovery

- deficit

- natural history deficits tended to be more likely to develop a new deficit postoperatively $(p=0.05)$. At the time of surgery, $55 \%$ had a motor deficit. Recovery of motor function was seen in $95 \%$ of patients within 1 year, and 14\% developed new postoperative motor deficits by final follow-up. Of those patients who developed a new motor deficit postoperatively, $76 \%$ did so at an adjacent level.

Conclusions In our series, a high percentage of patients recovered neurologic function during the first year after ACDF. Adjacent-level and remote-level degeneration were large contributors to neurologic deficits that occurred in subsequent years.
\end{abstract}

\section{Introduction}

Cervical radiculopathy is a disorder of the cervical nerve root, manifesting as any combination of pain or sensory or motor disturbance. ${ }^{1}$ When radiculopathy caused by compression of the effect nerve root proves recalcitrant to conservative modalities, anterior cervical discectomy and fusion (ACDF) is a widely accepted surgical treatment option. ${ }^{2-4}$ Following ACDF, resolution of pain and recovery of neurologic function are expected outcomes. ${ }^{5,6}$

received

June 17, 2013

accepted after revision

September 20, 2013

published online

November 15, 2013

To date, there is a paucity of literature that quantitatively characterizes neurologic recovery after ACDF. Historical rates of neurologic recovery have ranged from 36 to $93 \%$ within the first 2 years after ACDF. ${ }^{7-10}$ Unfortunately, none of these studies characterized neurologic deficits according to level, and outcomes were not ubiquitously separated into motor and sensory components.

In a seminal investigation by Hilibrand et $\mathrm{al}^{11}{ }^{11} 2.9 \%$ of patients per year developed symptoms at levels adjacent to the surgical level. Although previous studies have suggested

(c) 2014 Georg Thieme Verlag KG Stuttgart · New York
DOI http://dx.doi.org/ 10.1055/s-0033-1360723. ISSN 2192-5682. 
that a high percentage of patients recover neurologic function within the first 2 years after surgery, the role that adjacentlevel degeneration plays in those who do not recover is unknown. As such, the purpose of the current study was to elucidate the natural history of neurologic function after ACDF. Based on clinical experience, we hypothesized that a vast majority of patients would experience complete recovery of neurologic function and that adjacent-level degeneration would be a major contributor to deficits arising after an initial period of recovery.

\section{Materials and Methods}

\section{Study Protocol}

Following institutional review board approval, we reviewed a single-center, prospectively assembled surgical database for patients who underwent ACDF between April 1996 and May 2009. Patients between the ages of 18 and 80 at surgery, diagnosed with cervical radiculopathy, undergoing singlelevel ACDF, and followed for a minimum of 2 years were included. Patients with a history of spine infection or tumor, cervical spine fracture, traumatic spinal cord injury, cervical myelopathy, or prior cervical spine surgery were excluded. Two fellowship-trained spine surgeons performed the operations. We identified 312 consecutive patients who met all inclusion and exclusion criteria; 118 (38\%) with at least 2-year follow-up were included. Demographic, procedural, and medical data were abstracted from both our orthopedic database as well as our hospital's general medical records. Follow-up visits that were found to have incomplete documentation of physical exam findings were not included in our final data.

\section{Outcome Measures}

Sensory and motor deficits were graded based on physical examination findings performed by the attending surgeon for that case at preoperative, 6-week, 3-month, 6-month, 1-year, 2 -year, and most recent postoperative follow-up visits. Motor strength was objectively rated as normal or abnormalanything less than 5/5 strength-in each of five different muscle groups: deltoid (C5), biceps and/or wrist extensors (C6), triceps and/or wrist flexors (C7), grip (C8), and interossei (T1). ${ }^{12}$ Likewise, sensory function was graded as hypoesthetic for any sensory disturbance to light touch or normal in each dermatome from C3 to T1. ${ }^{12}$ Postoperative neurologic events were defined as any new deficit found at a level inconsistent with the preoperative or earlier postoperative findings. Rates of neurologic recovery were calculated based on the number of patients who experienced resolution of preoperative symptoms by 1 year postoperatively. The incidence of new deficits was calculated for both motor and sensory function based on newly identified neurologic events.

\section{Statistical Analysis}

Descriptive statistics (i.e., mean, standard deviation, and rate) were calculated for the 118-patient series. Fisher exact test was utilized to compare the rates of categorical variables. The two-tailed threshold of statistical significance was set at $p<0.05$

\section{Results}

Baseline demographic characteristics are summarized in -Table 1. The 118 patients had a mean age of $46 \pm 9.2$ years and mean follow-up of $3.8 \pm 2.1$ years. The ratio of males to females was $1: 1$. Although $31 \%$ of patients were habitual cigarette smokers, $5.9 \%$ were diagnosed with diabetes. We were unable to detect that habitual cigarette smoking or diabetes predisposed to a preoperative neurologic deficit, although our study was not powered adequately for definitive conclusions on these specific confounders. Preoperatively, $66 \%$ (78/118) of patients had sensory deficits, and 55\% (65/ 118) had motor deficits. By the end of the first year of followup, $85 \%$ (66/78) of preoperative sensory deficits had resolved, and $95 \%$ (62/65) of preoperative motor deficits had resolved.

Of 118 patients included in the sensory deficit analysis, $30 \%(35 / 118)$ had developed a new sensory deficit by final follow-up (-Fig. 1). New deficits arose at the index level in $60 \%$ (21/35), an adjacent level in 63\% (22/35), and a remote (i. e., nonadjacent) level in 26\% (9/35) of patients with new deficits. Patients with a preoperative sensory deficit tended to more frequently develop a new postoperative sensory deficit, but this did not reach statistical significance ( $p=0.05$; - Table 2). These patients also tended to develop new index-level sensory deficits at a relatively higher frequency, but this disparity also did not reach statistical significance $(p=0.07)$. Multilevel deficits where found in $40 \%$ (14/35) of patients who had new postoperative sensory deficits. Of the 21 patients who developed new same-level postoperative sensory deficit, 29\% (6/21) had radiographic evidence of pseudarthrosis, and the specific reason for a new same-level deficit in the remaining 71\% (15/21) was not determined. In addition to the new cervical sensory deficits that were documented, 3 patients were diagnosed with carpal tunnel syndrome, 1 was diagnosed with new peripheral neuropathy, and 3 patients had a transient loss of sensory function documented only on one exam during the first 3 months postoperatively.

A total of 118 patients were included in the motor deficit analysis; $14 \%(17 / 118)$ had a new motor deficit by the final follow-up visit (-Fig. 2). Of those patients with new deficits,

Table 1 Demographics

\begin{tabular}{|l|c|}
\hline Age $(y)$, mean \pm SD & $45.6 \pm 9.2$ \\
\hline Gender, $n(\%)$ & $60(50.9)$ \\
\hline Male & $58(49.2)$ \\
\hline Female & \\
\hline Smokers, $n(\%)$ & $37(31.4)$ \\
\hline Yes & $81(68.6)$ \\
\hline No & \\
\hline Diabetes status, $n(\%)$ & $7(5.9)$ \\
\hline Yes & $111(94.1)$ \\
\hline No & \\
\hline
\end{tabular}

Abbreviation: SD, standard deviation. 


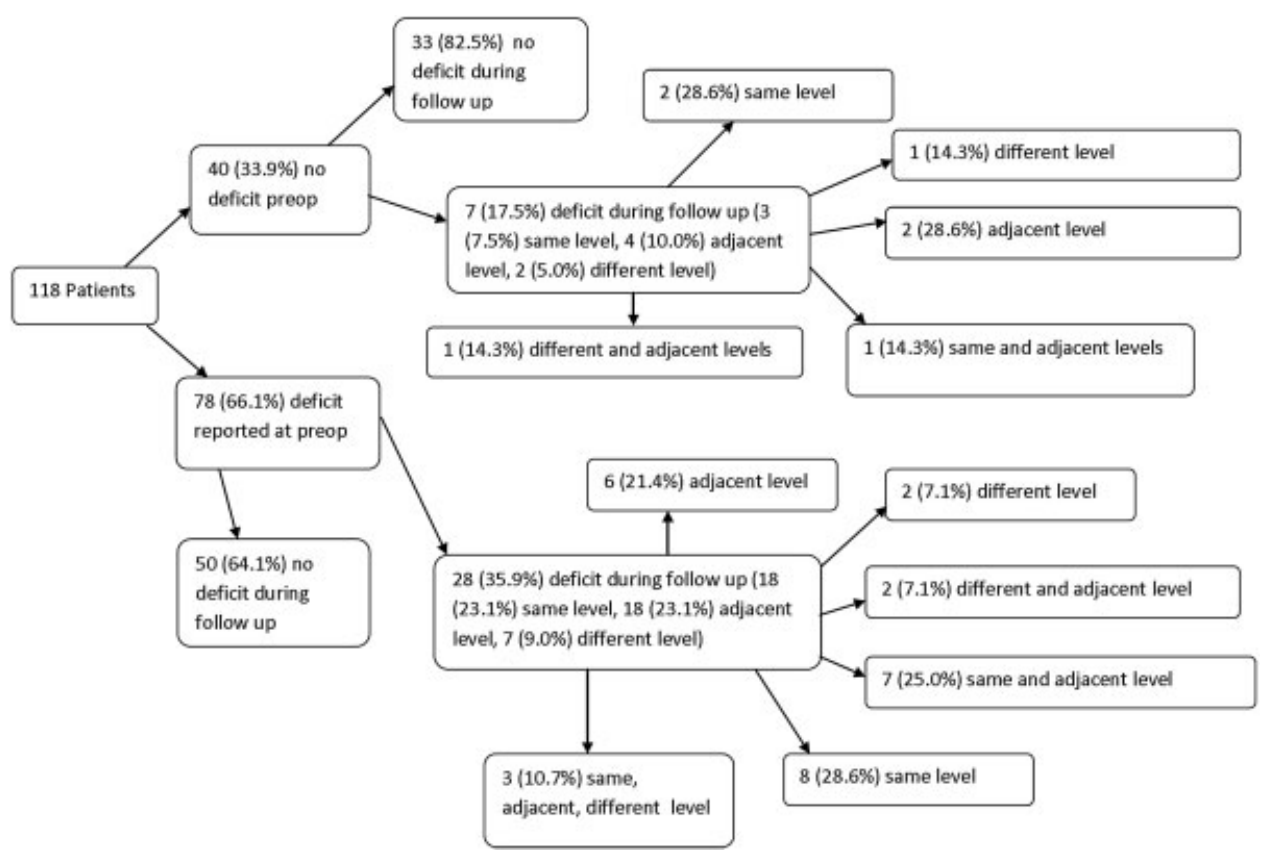

Fig. 1 Flowchart of sensory deficit analysis: Patients classified according to existence of preoperative sensory deficit, and then by occurrence of new postoperative sensory deficit at the same level (surgical level), adjacent level, a different level, or any combination of the prior three.

47\% (8/17) had same-level deficits, $76 \%(13 / 17)$ had adjacent-level deficits, and $47 \%(8 / 17)$ had deficits at a remote level. There were no significant differences with respect to new motor deficits between patients who did and did not have a preoperative motor deficit (-Table 3 ). Of the 8 patients who developed same-level postoperative motor deficits, none $(0 / 8)$ were found to have radiographic evidence of pseudarthrosis. Multilevel deficits were found in
$59 \%$ (10/17) of patients who developed new postoperative motor deficits.

\section{Discussion}

To our knowledge, this is the first investigation to specifically focus on the natural history of neurologic function following ACDF. To provide clinically relevant information

Table 2 Comparison of patients with versus without preoperative sensory deficit

\begin{tabular}{|c|c|c|c|c|c|}
\hline & \multicolumn{2}{|c|}{$\begin{array}{l}\text { No } \\
\text { preoperative } \\
\text { sensory } \\
\text { deficit } \\
(n=40)\end{array}$} & \multicolumn{2}{|c|}{$\begin{array}{l}\text { Preoperative } \\
\text { sensory } \\
\text { deficit } \\
(n=78)\end{array}$} & \multirow[b]{2}{*}{$p^{\mathrm{a}}$} \\
\hline & $n$ & $\%$ & $n$ & $\%$ & \\
\hline Sensory deficit at the surgical level present during follow-up ${ }^{b}$ & & & & & 0.07 \\
\hline Yes & 3 & 8.1 & 18 & 23.7 & \\
\hline No & 34 & 91.9 & 58 & 76.3 & \\
\hline Sensory deficit at an adjacent level to the surgical level present during follow-up & & & & & 0.13 \\
\hline Yes & 4 & 10.0 & 18 & 23.1 & \\
\hline No & 36 & 90.0 & 60 & 76.9 & \\
\hline Sensory deficit at a different level to the surgical level present during follow-up & & & & & 0.72 \\
\hline Yes & 2 & 5.0 & 7 & 9.0 & \\
\hline No & 38 & 95.0 & 71 & 91.0 & \\
\hline Any sensory deficit during follow-up & & & & & 0.05 \\
\hline Yes & 7 & 17.5 & 28 & 35.9 & \\
\hline No & 33 & 82.5 & 50 & 64.1 & \\
\hline
\end{tabular}

${ }^{a} p$ value based on Fisher exact test.

bFive patients not included because the surgical site ( $\mathrm{C} 4$ or $\mathrm{T} 1$ ) cannot have same-site deficits. 


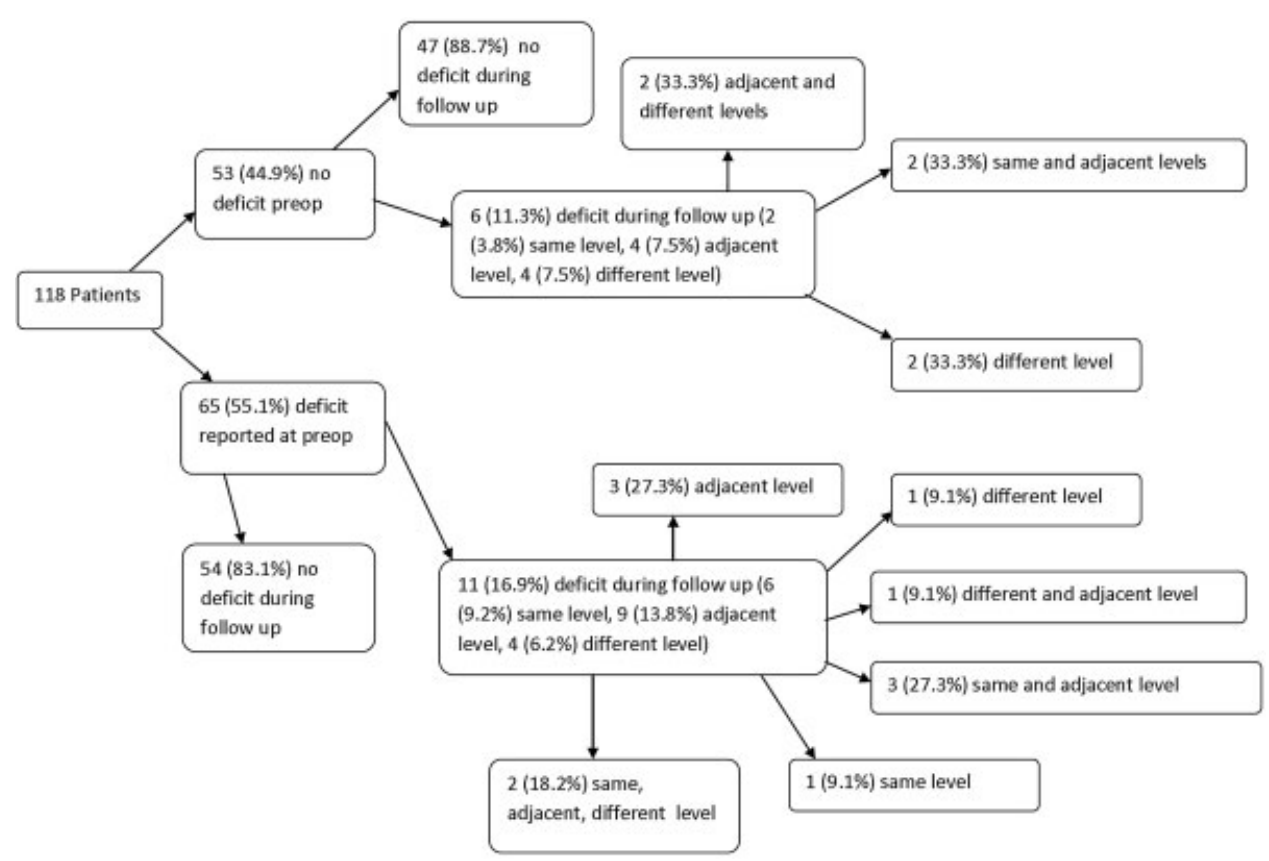

Fig. 2 Flowchart of motor deficit analysis: Patients classified according to existence of preoperative motor deficit, and then by occurrence of new postoperative motor deficit at the same level (surgical level), adjacent level, a different level, or any combination of the prior three.

for physicians and patients, our first purpose was to examine rates of recovery for both motor and sensory function after ACDF. Second, we sought to quantitatively characterize the impact of adjacent-level degeneration on new neurologic deficits that appear after ACDF.

In accordance with our hypothesis and the literature, the vast majority of patients with a neurologic deficit recovered complete function within the first postoperative year. ${ }^{5-7,9,13}$
Furthermore, our investigation showed that a higher percentage of patients with motor deficits recovered than those with sensory deficits. Again, this was expected based on the authors' collective clinical experience, but the reason for these findings remains unclear.

A substantial percentage of the patients (30\%) in our series experienced new sensory deficits by final follow-up. Contrary to our hypothesis, new deficits occurred throughout the

Table 3 Comparison of patients with versus without preoperative motor deficit

\begin{tabular}{|c|c|c|c|c|c|}
\hline & \multicolumn{2}{|c|}{$\begin{array}{l}\text { No } \\
\text { preoperative } \\
\text { motor } \\
\text { deficit } \\
(n=53)\end{array}$} & \multicolumn{2}{|c|}{$\begin{array}{l}\text { Preoperative } \\
\text { motor } \\
\text { deficit } \\
(n=65)\end{array}$} & \multirow[b]{2}{*}{$p^{\mathrm{a}}$} \\
\hline & $n$ & $\%$ & $n$ & $\%$ & \\
\hline Motor deficit at the surgical level present during follow-up ${ }^{b}$ & & & & & 0.30 \\
\hline Yes & 2 & 3.9 & 6 & 9.2 & \\
\hline No & 50 & 96.2 & 59 & 90.8 & \\
\hline Motor deficit at an adjacent level to the surgical level present during follow-up & & & & & 0.38 \\
\hline Yes & 4 & 7.6 & 9 & 13.9 & \\
\hline No & 49 & 92.5 & 56 & 86.2 & \\
\hline Motor deficit at a different level than the surgical level present during follow-up & & & & & $>0.99$ \\
\hline Yes & 4 & 7.6 & 4 & 6.2 & \\
\hline No & 49 & 92.5 & 61 & 93.9 & \\
\hline Any motor deficit during follow-up & & & & & 0.44 \\
\hline Yes & 6 & 11.3 & 11 & 16.9 & \\
\hline No & 47 & 88.7 & 54 & 83.1 & \\
\hline
\end{tabular}

${ }^{a} p$ value based on Fisher exact test.

${ }^{\mathrm{b}}$ One patient not included because the surgical site (C4) cannot have same-site deficits. 
cervical spine, including an approximately equal number of deficits at the surgical level as at an adjacent level, with a slightly lower percentage occurring at remote levels. A radiographic diagnosis of pseudarthrosis accounted for only $29 \%$ of patients with new postoperative sensory events at the same level. The remainder of new postoperative samelevel sensory deficits could have been due to either relapse of preoperative deficits or overlap of dermatomes from adjacent-level sensory deficits. ${ }^{6,14-17}$ Novel dysfunction arising at adjacent and remote levels suggests the natural progression of cervical spondylosis plays a pivotal role in new neurologic deficits observed years later. Overall, patients with preoperative sensory deficits were more prone to new postoperative sensory events. This suggests that preoperative sensory deficits predispose to subsequent neurologic deficits.

New postoperative motor deficits (14\%) were considerably less frequent in our study than new sensory deficits (30\%). Although motor deficits were also less frequent preoperatively, a considerably higher percentage of new postoperative deficits occurred at an adjacent level (76\%) than at a remote level (47\%) or the surgical level (47\%). None of the new same-level postoperative motor deficits were accounted for by pseudarthrosis. Similar to sensory findings, it is likely that these deficits either represent a recurrence of preoperative deficits or an overlap of myotomes from adjacent levels. The high percentage of new motor deficits that occurred either at an adjacent level or a remote level further supports the progression of cervical spine degenerative disease as a major contributor to new postoperative motor deficits.

In a U.S. Food and Drug Administration prospective randomized controlled trial comparing ProDisc-C (Synthes Spine Company, L.P., West Chester, Pennsylvania, United States) total disk replacement and ACDF for the treatment of cervical radiculopathy, neurologic outcomes were reported at 6month and 2-year follow-up. ${ }^{8}$ Neurologic success was defined as objective maintenance of or improvement in sensory, motor, and reflex function on clinical examination. At 6month and 2-year follow-up, 85 and $88 \%$ of patients had achieved neurologic success, respectively. In another Investigational Device Exemption trial, neurologic outcomes were reported at 3-month, 6-month, 1-year, and 2-year follow-up. These authors compared the PRESTIGE ST Cervical Disc System (Medtronic Sofamor Danek, Memphis, Tennessee, United States) to ACDF for the treatment of cervical radiculopathy. Neurologic success was defined identically to the ProDisc-C trial. At 6-month and 2-year follow-up, 90 and 84\% of patients achieved neurologic success. Unfortunately, neither of these pivotal trials subdivided neurologic function into motor and sensory components, and the cervical levels of the deficits were not identified.

In 1993, Bohlman et $\mathrm{al}^{7}$ reported the long-term follow-up of 122 patients who underwent one- to four-level ACDF for cervical radiculopathy. With a mean follow-up of 6 years, 71 of 77 patients with a preoperative sensory deficit regained function at the effected level. New sensory deficits at adjacent levels were not described.
High rates of neurologic recovery after ACDF for myelopathy have also been reported. Emery et al reported on 108 patients who underwent ACDF for myelopathy with a minimum follow-up of 2 years. ${ }^{18}$ Preoperatively, 87 patients had motor weakness in at least one extremity and 89 had sensory weakness in at least one extremity. Postoperatively, $62 \%$ of those with motor deficits had complete recovery and 30\% had partial recovery of their symptoms, and $48 \%$ of those with sensory deficits had complete recovery and 39\% had partial recovery of their symptoms. Chiles et al also reported neurologic outcomes after ACDF for cervical myelopathy of 76 patients with a mean follow-up of 8.9 months. ${ }^{19}$ Motor deficits saw some improvement in 79 to $91 \%$ of patients depending on the muscle group involved. Akin to our study, both of these studies demonstrated high rates of neurologic recovery after ACDF.

Our study was limited by its retrospective design and by natural variations in human neuroanatomy. Although 312 consecutive patients were eligible for the study, only 118 were ultimately analyzed due to insufficient follow-up data. Attempts were made to contact patients with a least 1 year of follow-up for reexamination. Because our study does not represent a complete consecutive series, it is possible that the overall incidence of new postoperative deficits is over- or underestimated.

Although we attempted to quantify both sensory and motor deficits according to classic dermatomal and myotomal distributions, anatomical variation is inevitable. ${ }^{14}$ For example, classically, the C6 sensory dermatome localizes to the lateral two fingers and forearm, the $\mathrm{C} 7$ dermatome localizes to the middle finger, and the $\mathrm{C} 8$ dermatome localizes to the medial two fingers and forearm. In clinical practice, however, there is occasionally dermatomal overlap, making it relatively more difficult to identify the level from which a deficit is truly emanating. ${ }^{15-17}$ Anatomical variation may partially account for the fact that many patients in our study had multilevel neurologic deficits.

Clinically, patients with preoperative neurologic deficits can be counseled on high rates of recovery of sensory and motor function during the first year after ACDF. In subsequent years, patients can expect to have a moderate rate of new sensory disturbances with a lower rate of new motor disturbances secondary to progression of spondylotic disease throughout the cervical spine. If recurrent neurologic dysfunction occurs at the surgical level, other sources should be investigated, including pseudarthrosis or other peripheral sensory disturbance. Although progression of cervical spondylotic disease may not be avoidable, one should avoid violating adjacent-level disks during surgery, the number of levels fused should be minimized, or cervical arthroplasty could be considered. These techniques could help to reduce the progression of cervical spondylotic disease at adjacent and remote levels.

In conclusion, a high percentage of patients with both sensory and motor deficits recover neurologic function during the first year after ACDF. Adjacent-level and remote-level progression of cervical spondylotic disease appear to be large contributors to neurologic deficits seen in subsequent years. 


\section{Note}

Investigation performed at the Department of Orthopaedic Surgery at Washington University in St. Louis, St. Louis, Missouri, United States.

\section{Disclosures}

No outside funding was received for this study.

\section{References}

1 Rhee JM, Yoon T, Riew KD. Cervical radiculopathy. J Am Acad Orthop Surg 2007;15(8):486-494

2 Bono CM, Ghiselli G, Gilbert TJ, et al; North American Spine Society. An evidence-based clinical guideline for the diagnosis and treatment of cervical radiculopathy from degenerative disorders. Spine J 2011;11(1):64-72

3 Peolsson A, Peolsson M. Predictive factors for long-term outcome of anterior cervical decompression and fusion: a multivariate data analysis. Eur Spine J 2008;17(3):406-414

4 Gebremariam L, Koes BW, Peul WC, Huisstede BM. Evaluation of treatment effectiveness for the herniated cervical disc: a systematic review. Spine (Phila Pa 1976) 2012;37(2):E109-E118

5 Sampath P, Bendebba M, Davis JD, Ducker T. Outcome in patients with cervical radiculopathy. Prospective, multicenter study with independent clinical review. Spine (Phila Pa 1976) 1999;24(6):591-597

6 Persson LC, Moritz U, Brandt L, Carlsson CA. Cervical radiculopathy: pain, muscle weakness and sensory loss in patients with cervical radiculopathy treated with surgery, physiotherapy or cervical collar. A prospective, controlled study. Eur Spine J 1997; 6(4):256-266

7 Bohlman HH, Emery SE, Goodfellow DB, Jones PK. Robinson anterior cervical discectomy and arthrodesis for cervical radiculopathy. Long-term follow-up of one hundred and twenty-two patients. J Bone Joint Surg Am 1993;75(9):1298-1307

8 Murrey D, Janssen M, Delamarter R, et al. Results of the prospective, randomized, controlled multicenter Food and Drug Administration investigational device exemption study of the ProDisc- $C$ total disc replacement versus anterior discectomy and fusion for the treatment of 1-level symptomatic cervical disc disease. Spine J 2009;9(4):275-286

9 Mummaneni PV, Burkus JK, Haid RW, Traynelis VC, Zdeblick TA. Clinical and radiographic analysis of cervical disc arthroplasty compared with allograft fusion: a randomized controlled clinical trial. J Neurosurg Spine 2007;6(3):198-209

10 Jagannathan J, Shaffrey CI, Oskouian RJ, et al. Radiographic and clinical outcomes following single-level anterior cervical discectomy and allograft fusion without plate placement or cervical collar. J Neurosurg Spine 2008;8(5):420-428

11 Hilibrand AS, Carlson GD, Palumbo MA, Jones PK, Bohlman HH. Radiculopathy and myelopathy at segments adjacent to the site of a previous anterior cervical arthrodesis. J Bone Joint Surg Am 1999;81(4):519-528

12 Hoppenfeld S, Hutton R. Physical Examination of the Spine and Extremities. New York, NY: Appleton-Century-Crofts; 1976

13 Garrido BJ, Taha TA, Sasso RC. Clinical outcomes of Bryan cervical disc arthroplasty a prospective, randomized, controlled, single site trial with 48-month follow-up. J Spinal Disord Tech 2010;23(6): 367-371

14 Ozgur BM, Marshall LF. Atypical presentation of C-7 radiculopathy. J Neurosurg 2003;99(2, Suppl):169-171

15 Bertilson BC, Grunnesjö M, Strender LE. Reliability of clinical tests in the assessment of patients with neck/shoulder problems-impact of history. Spine (Phila Pa 1976) 2003;28(19): 2222-2231

16 Slipman CW, Plastaras CT, Palmitier RA, Huston CW, Sterenfeld EB. Symptom provocation of fluoroscopically guided cervical nerve root stimulation. Are dynatomal maps identical to dermatomal maps? Spine (Phila Pa 1976) 1998;23(20):2235-2242

17 Wainner RS, Fritz JM, Irrgang JJ, Boninger ML, Delitto A, Allison S. Reliability and diagnostic accuracy of the clinical examination and patient self-report measures for cervical radiculopathy. Spine (Phila Pa 1976) 2003;28(1):52-62

18 Emery SE, Bohlman HH, Bolesta MJ, Jones PK. Anterior cervical decompression and arthrodesis for the treatment of cervical spondylotic myelopathy. Two to seventeen-year follow-up. J Bone Joint Surg Am 1998;80(7):941-951

19 Chiles BW III, Leonard MA, Choudhri HF, Cooper PR. Cervical spondylotic myelopathy: patterns of neurological deficit and recovery after anterior cervical decompression. Neurosurgery 1999;44(4):762-769, discussion 769-770 